\title{
Retained metabolic activity in honey bee collected pollen has implications for pollen digestion and effects on honey bee health
}

\author{
Mia McKinstry, Sofia R. Prado-Irwin, Tara Reyes Adames, Jonathan W. Snow
}

Biology Department, Barnard College, New York, NY 10027, USA

Received 12 March 2019 - Revised 2 September 2019 - Accepted 9 October 2019

\begin{abstract}
The mechanisms by which pollen is digested by honey bees are incompletely understood. Potential methods are thought to include pseudogermination, mechanical disruption, enzymatic breakdown, or osmotic shock. Understanding the role of pseudogermination in this process has been hampered by a lack of tools demonstrating retention of metabolic activity in pollen collected by honey bees. Here, we show that pollen collected by honey bees produces reactive oxygen species (ROS) at robust levels upon germination, suggesting that ROS is a suitable marker of this process in pollen. ROS can be readily found in the digestive tract of honey bees and is localized to pollen grains within the lumen. Finally, manipulating pollen levels in the midgut can change ROS levels in the digestive tract. These data provide evidence of retained metabolic activity in bee-collected pollen that lends support to pseudogermination as a mechanism for pollen digestion in honey bees, and points to novel approaches for better understanding of pollen digestion in this species and beyond.
\end{abstract}

ecology / honey bee / pollen / pollinator / digestion

\section{INTRODUCTION}

Simply defined, pollination is the transfer of a pollen grain from the anther of one flower to the stigma of the same or another flower. Many plants rely on pollinators to facilitate this process, providing nutrients to pollinators in exchange for the reproduction-enabling service of pollination (reviewed in (Waser and Ollerton 2006)). The western honey bee, Apis mellifera, is a vitally important participant in this process in both

Electronic supplementary material The online version of this article (https://doi.org/10.1007/s13592-019-00703-x) contains supplementary material, which is available to authorized users.

Corresponding author: J.W. Snow, jsnow@barnard.edu Manuscript editor: James Nieh agricultural and ecological settings (reviewed in (Potts et al. 2016)).

For honey bees, pollen represents an important nutrient source (reviewed in (Wright et al. 2018)), but the way it is digested in this species is incompletely understood. Pollen grains contain 1-2 sperm cells and one vegetative cell which are protected by an inner layer (intine) and a tough outer layer (exine) and are dehydrated and metabolically inactive for dispersal (reviewed in \{Borg:2011ee\}). In other palynivorous species, pollen digestion is thought to involve one or several of the following mechanisms: induction of germination/pseudogermination, mechanical disruption of the pollen wall, enzymatic breakdown, and osmotic shock (Roulston and Cane 2000). Current evidence supports of two of these four pathways for pollen digestion in honey bees: pseudogermination and osmotic shock (Peng and Dobson 1997). 
Osmotic shock occurs when the osmotic pressure differential between the crop and ventriculus causes the pollen grain to rupture when traversing between these compartments. In vitro evidence suggests this process may occur in honey bee digestion (Kroon et al. 1974). However, in situ studies demonstrate a slow loss of pollen contents in the midgut, in line with an enzymatic digestion or pseudogermination process as opposed to osmotic shock (Klungness and Peng 1983; Klungness and Peng 1984a; Klungness and Peng 1984b; Peng et al. 1985; Peng et al. 1986; Human and Nicolson 2003). Once the contents of the pollen grain are unprotected, digestion of macromolecules proceeds, via enzymes that are likely produced by both honey bee epithelial cells and resident microbiota (Wright et al. 2018).

Pseudogermination occurs when the pollen grain initiates a germination sequence, but is interrupted prior to full pollen tube formation. A significant body of work shows that pollen collected and stored by honey bees has reduced capacity to pollinate female flowers, in part due to loss of germination potential (Singh and Boynton 1949; Griggs and Vansell 1950; Griggs et al. 1953; Johansen 1956; Kraai 1962; Free and Durrant 1966; Klungness et al. 1983; Mesquida and Renard 1989; Vaissiere et al. 1996). Post collection, further processing and storage in the comb may change germination potential as well. A pseudogermination mechanism of digestion would require that some aspects of germination, such as metabolic activity, remain intact despite the loss of germination potential. While older studies suggest that progressive microbiological and biochemical changes render honey bee stored and consumed pollen metabolically inactive (Gilliam 1997), recent studies suggest that the biochemical and microbiological characteristics of pollen do not change substantially upon collection or typical storage as bee bread (Human and Nicolson 2006; Nicolson and Human 2013; Anderson et al. 2014).

The aforementioned studies predominantly focused on pollen germination as defined by pollen tube formation or fertilization potential, both of which concern late or final events in the germination process. By contrast, pseudogermination is likely to be an interrupted process. Recent advances in our understanding of the cellular and molecular steps involved in the early stages of germination may provide novel tools for understanding the process of pseudogermination. For example, germination results in the production of an early "wave" of reactive oxygen species (ROS) that provides key signaling cues for pollen function (reviewed in (McInnis et al. 2006)). We therefore propose that a ROS burst in honey beecollected pollen could provide additional evidence of retained metabolic activity and potential pseudogermination during honey bee pollen digestion. Here, we show that pollen collected by honey bees from multiple plant species produces ROS at robust levels upon germination, both in vitro and in the lumen of the digestive tract. Further, we show that manipulating pollen levels in the midgut can change ROS levels in the digestive tract. These data provide evidence of retained metabolic activity in bee-collected pollen that lends support to pseudogermination during pollen digestion in honey bees, and points to novel approaches for better understanding of pollen digestion in this species and beyond.

\section{MATERIALS AND METHODS}

\subsection{Honey bee and pollen collection}

Honey bees were collected from outbred colonies in New York, NY, during the months of April-October in 2014 and 2015. Colonies were visually inspected for symptoms of common diseases, and only visibly healthy bees were collected. For feeding experiments, bees returning to the hive without pollen loads were collected. Pollen used for in vitro germination and feeding experiments was collected from the corbiculae of returning foragers from the colonies above (Figure 1a).

\subsection{Species identification of honey bee- collected pollen}

To determine the species identity of pollen collected by honey bees, the rRNA internal transcribed spacer 2 (ITS2) region was sequenced for one of two paired pollen loads on the corbiculae of a single forager. The other paired pollen load 
was used immediately in the Amplex Red assay (see below) to assess ROS production. Honey bees are well known to display flower constancy, preferring to visit flowers of the same species in a foraging trip (reviewed in (Brodschneider et al. 2018)). In fact, it has been found that less than $3 \%$ of pollen loads are mixed in pollen composition (Betts 1935). To obtain ITS2 sequence from pollen, RNA was extracted using Trizol Reagent (Invitrogen, San Diego, CA) per manufacturer's instruction after manually crushing the pollen with a disposable pestle. cDNA was synthesized using the iScript cDNA Synthesis Kit (Biorad, Hercules, CA) and 1-5 $\mu$ l of cDNA was then used as a template for PCR using universal plant ITS2 primer sequences used (ITS2F: 5'- ATGCGATA CTTGGTGTGAAT-3' and ITS3R: 5' GACGCTTCTCCAGACTACAAT-3'). PCR was performed with using the GoTaq polymerase and buffer (Promega, Madison, WI); cycling conditions have been described elsewhere (Chen et al. 2010). After visualizing a fraction of the PCR products on a gel, the remainder was purified using a QIAGEN PCR Purification Kit (Genewiz, $\mathrm{NJ}$ ) and sequenced using Sanger sequencing sequences were annotated and the genus (and highest ranked species) of the plant of origin was identified using the ITS2 Database (Koetschan et al. 2009).

\subsection{Pollen counts}

Pollen grains were diluted to $10 \mu \mathrm{g} / \mu \mathrm{l}$ in PBS and boli were crushed in $600 \mu$ for the Amplex Red assay above. For pollen from midgut contents, an aliquot of $50 \mu \mathrm{l}$ was stained with Safranin O for pollen counting (Jones 2012). Pollen counts for a known area of the slide were made using a Nikon SMZ1500 stereo zoom microscope and multiplied by the whole slide area. The total number of pollen grains was calculated using total volume of the sample and total area of the slide.

\subsection{Visualization of ROS in pollen and food boli}

Pollen was collected from the corbiculae of returning foragers and analyzed on the day of acquisition. Pollen grains were hydrated in PBS
Figure 1. Reactive oxygen species (ROS) production in honey bee-collected pollen. a Typical pollen load on the corbiculae of foragers returning to the hive. b Beecollected pollen grains assayed for ROS presence using CM- $\mathrm{H}_{2}$ DCF. Fluorescence indicates ROS. From top: (i) Control with no CM- $\mathrm{H}_{2} \mathrm{DCF}$ dye, (ii) $\mathrm{CM}-\mathrm{H}_{2} \mathrm{DCF}$ dye without inhibitors, (iii) $\mathrm{CM}-\mathrm{H}_{2} \mathrm{DCF}$ dye with inhibitor $\mathrm{N}$-acetyl cysteine (NAC), (iv) $\mathrm{CM}-\mathrm{H}_{2} \mathrm{DCF}$ dye with inhibitor ascorbic acid (AA). Left panels are brightfield images, right panels are phase-contrast images $(\times 100$ magnification, scale bar $=0.1 \mathrm{~mm}$ ).

and diluted to $10 \mu \mathrm{g} / \mathrm{ul}$. To examine ROS within the midgut lumen, the food bolus was removed from the midgut by removing the peritrophic matrix and its contents as before (Masood et al. 2016).

For ROS detection in both pollen and midgut food bolus samples, samples were incubated at room temperature for $20 \mathrm{~min}$ with $0.1 \mathrm{mM} \mathrm{5-}$ ( a n d - 6 ) - c h 1 o r o m e th y $1-2^{\prime}, 7^{\prime}$ dichlorodihydrofluorescein diacetate, acetyl ester (CM-H 2 DCFDA; Molecular Probes, Eugene, Ore) in reaction buffer as per manufacturer's instructions. For food bolus samples, fluorescence was also recorded prior to adding $C M-H 2$ $D C F D A$ to assess the presence of auto-fluorescence. ROS-generated fluorescence was visualized by a Nikon SMZ1500 stereo zoom microscope with brightfield/darkfield base, fluorescence unit, and Nikon Digital Sight DS-Fil high-resolution digital camera, with controller and PC.

\subsection{Measurement of hydrogen peroxide}

Hydrogen peroxide in pollen was quantified as a measure of ROS production using the Amplex Red assay. For measurements of $\mathrm{H}_{2} \mathrm{O}_{2}$ in fresh pollen and bee bread, pollen grains were diluted to $10 \mu \mathrm{g} / \mu \mathrm{l}$ in PBS and $1 \mathrm{mg}$ was used per replicate of each assay condition. The assay was performed using the Amplex Red Assay (Invitrogen) as per the manufacturer's instructions with or without $200 \mathrm{mM} \mathrm{N}$-acetyl cysteine (NAC) or $50 \mathrm{mM}$ ascorbic acid (AA) in a final volume of $300 \mu \mathrm{l}$. For heat inhibition (HI), $1 / 2$ of the pollen was heated at $80{ }^{\circ} \mathrm{C}$ for $1 \mathrm{~h}$ before starting the assay. For pre-germination, $1 / 2$ of pollen was allowed to germinate for $2 \mathrm{~h}$, washed, and resuspended 
a

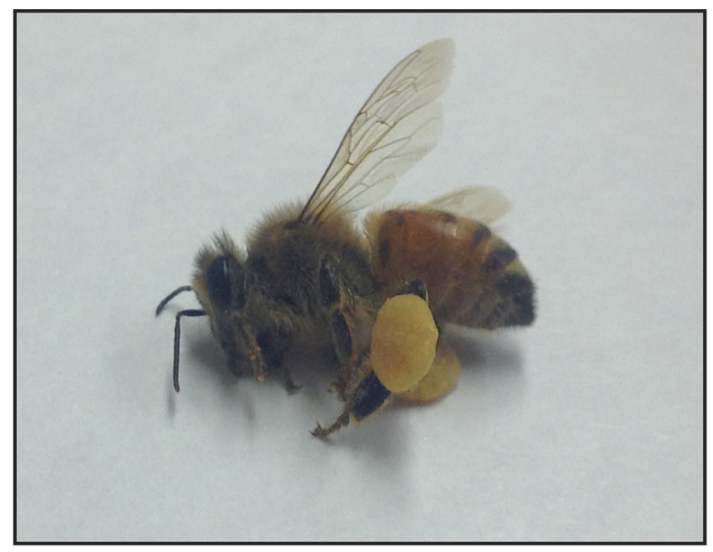

b

brightfield

fluorescence

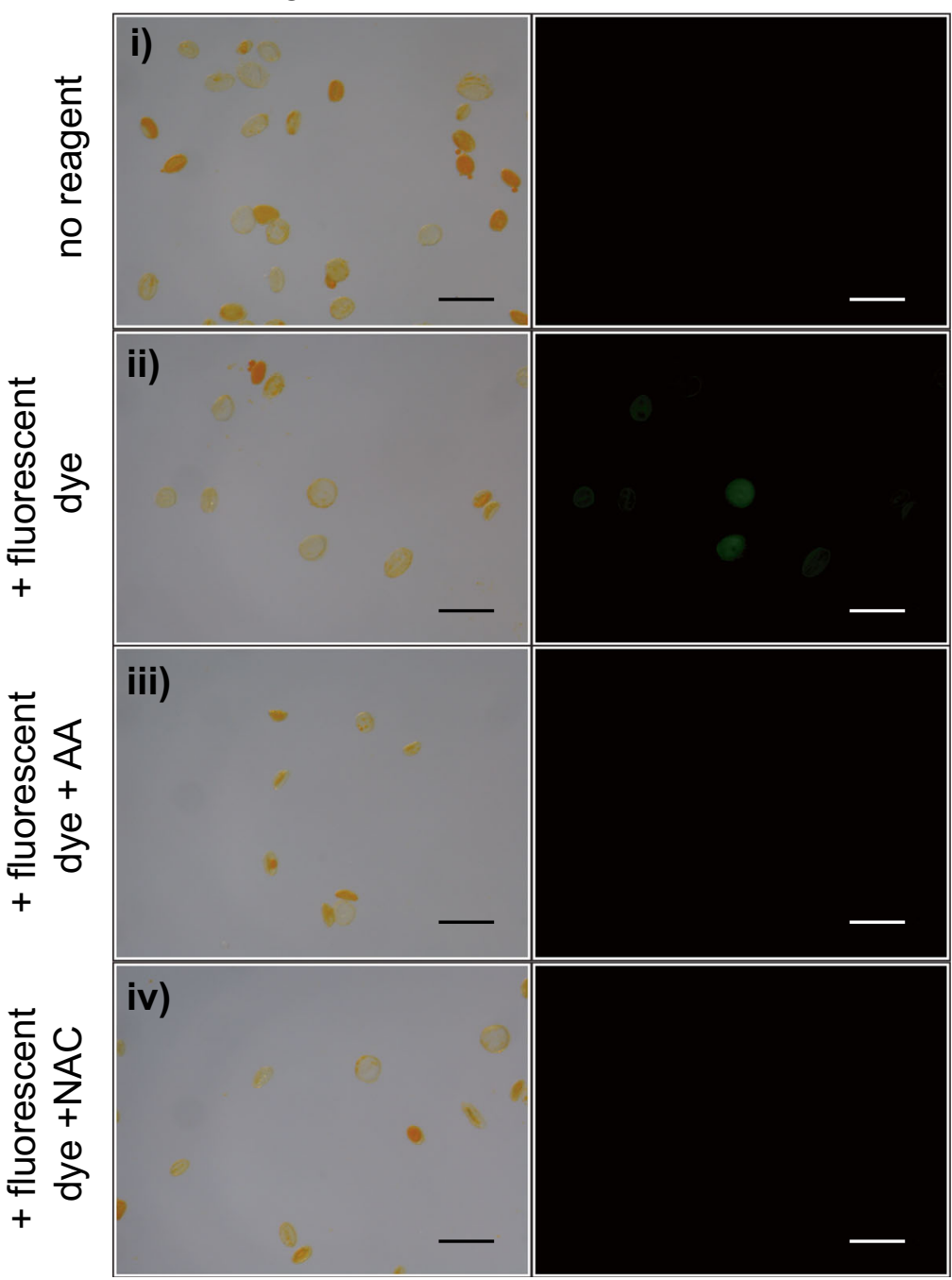


before starting the assay. After incubation at $37^{\circ} \mathrm{C}$ for $30 \mathrm{~min}$, the $\mathrm{H}_{2} \mathrm{O}_{2}$ level was measured spectrophotometrically at $560 \mathrm{~nm}$ (A560nm) using a GloMax-Multi Jr Single-Tube Multimode Reader (Promega). For each pollen sample, a negative control, in which only the Amplex red reagent was omitted, was performed.

For measurements of $\mathrm{H}_{2} \mathrm{O}_{2}$ in midgut food boli, each bolus was crushed in $600 \mu \mathrm{l}$ solution, and $100 \mu \mathrm{l}$ was used in each replicate of each assay condition. In the case of inhibitors, multiple boluses were mixed (again with a final concentration of $600 \mu \mathrm{l}$ per bolus). The assay was again performed using the Amplex Red Assay (Invitrogen) as per the manufacturer's instructions with or without $200 \mathrm{mM} \mathrm{N}$-acetyl cysteine (NAC) or $50 \mathrm{mM}$ ascorbic acid (AA) in a final volume of $300 \mu$ l. In addition, control samples without pollen or bolus, which were spiked with 0 or $10 \mu \mathrm{M}$ of $\mathrm{H}_{2} \mathrm{O}_{2}$ were performed for each experiment. Low signal was sometimes observed in food boluses without the Amplex Red reagent so this background was subtracted to obtain bolus ROS levels for individual bees.

\subsection{Measurement of superoxide anion production}

Superoxide anion concentration in collected pollen as a measure of ROS production was assessed using a nitroblue tetrazolium assay. Pollen grains were diluted to $10 \mu \mathrm{g} / \mathrm{ul}$ in PBS and $1 \mathrm{mg}$ was used per assay condition. The assay was performed using $2 \mathrm{mM}$ nitroblue tetrazolium (NBT) in a final volume of $300 \mu \mathrm{l}$. Mixtures were then incubated for $15 \mathrm{~min}$ at $37^{\circ} \mathrm{C}$. NBT was completely removed by repeated washing steps in PBS followed by a final methanol wash. The formazan precipitate was dissolved in $2 \mathrm{M} \mathrm{KOH}$ followed by dimethyl sulfoxide (DMSO) (Rook et al. 1985). Absorbance was determined at $530 \mathrm{~nm}(\mathrm{~A} 530 \mathrm{~nm})$ on a spectrophotometer (DU 530; Beckman Instruments, Fullerton, CA).

\subsection{Feeding treatments}

For all caged experiments, approximately 15 honey bees without pollen (unless otherwise noted) were selected from the landing board of colonies as above and kept in $177.4 \mathrm{~mL}$ (6 oz.) square-bottomed Drosophila Stock Bottles (VWR) plugged with modified foam tube plugs (Jaece Industries). Bees were maintained in incubators at $35{ }^{\circ} \mathrm{C}$ in the presence of PseudoQueen (Contech, Victoria, British Columbia, Canada) as a source of Queen Mandibular Phermone (QMP), which was used as per manufacturer's instructions. Bees were fed via a modified $1.5-\mathrm{ml}$ screw-cap tube. Bees were fed a diet of sucrose syrup alone for $24 \mathrm{~h}$, starved for $1 \mathrm{~h}$ to encourage feeding, and then fed $30 \%$ sucrose with or without monofloral or polyfloral pollen for $1 \mathrm{~h}$ (as described in the results) provided at a concentration of $50 \mathrm{mg} / \mathrm{ml}$. No differences in consumption were observed between groups and the mortality in these short-term experiments was essentially non-existent.

\subsection{Statistical analysis}

For all spectrophotometry data, mean values were calculated for each group. For in vitro assays, normality was assumed due to the small sample size. For in vivo assays, normality was assessed using Shapiro-Wilk tests or Kolmogorov-Smirnov as noted in the statisics table. Differences between two groups were compared using unpaired $t$ tests with Welch's correction when values fit normal distributions or MannWhitney $U$ nonparametric tests when they did not fit normal distributions. Differences between more than two groups were compared using ANOVA or Kruskal-Wallis test with post-hoc Tukey's multiple comparison test. All statistical data can be found in Supplemental Document 1 .

\section{RESULTS}

\subsection{Pollen ROS levels vary across different plant species}

We identified six plant species representing five genera in honey bee-collected pollen from different sampling periods (Table I). Using the Amplex Red assay, we observed variable levels of ROS production by pollen from different species in our assay, and some pollen types did not appear to produce ROS (Table I and Suppl. 
Table I. Species identification and ROS production activity of honey bee-collected pollen

\begin{tabular}{lll}
\hline \multicolumn{1}{c}{ Species } & Date collected & ROS production $\left(\mu \mathrm{M} \mathrm{H}_{2} \mathrm{O}_{2}\right)$ \\
\hline Plantago rugelii & $07 / 25 / 14$ & $0.23( \pm 0.094)^{\dagger}$ \\
Trifolium repens & $07 / 25 / 14$ & $5.47( \pm 0.123)^{* *}$ \\
Trifolium repens & $08 / 03 / 14$ & $4.98( \pm 0.025)^{* *}$ \\
Trifolium pretense & $08 / 03 / 14$ & $1.04( \pm 0.493)^{\dagger}$ \\
Styphnolobium japonicum & $08 / 04 / 14$ & $4.29( \pm 0.068)^{*}$ \\
Ageratina altissima & $10 / 03 / 13$ & $0.73( \pm 0.39)^{\dagger}$ \\
Ageratina altissima & $10 / 03 / 13$ & $2.05( \pm 0.46)^{*}$ \\
Symphyotrichum spathulatum & $10 / 03 / 13$ & $0.93( \pm 0.084)^{* *}$ \\
\hline
\end{tabular}

Mean with Amplex with mean of no Amplex control subtracted ( \pm SEM)

${ }^{\dagger}$ Not significantly different than no Amplex control

$* p<0.05$ relative to no Amplex control

$* * p<0.01$ relative to no Amplex control

Figure 1). However, at each time point, we found at least one plant species with metabolically active pollen. We also found that pollen samples from different genera produce variable levels of ROS upon germination (Table I).

\subsection{Honey bee-collected pollen produces robust ROS levels in vitro}

We found robust signal of ROS in pollen grains collected from corbiculae using the CMH2DCFDA indicator reagent (Figure 1b). We were able to eliminate the signal through the addition of antioxidants $\mathrm{N}$-acetyl cysteine (NAC) or ascorbic acid, (AA) demonstrating that the signal represents ROS.

We also found robust ROS signal in pollen grains using the Amplex Red Assay (Figure 2a). Again, the signal could be eliminated through the addition of antioxidants, demonstrating the signal is specific for ROS (Figure 2b). We also found that the signal could be eliminated through heat inhibition (HI), demonstrating the signal is dependent on active enzymes in living pollen (Figure 2c). In addition, pre-germination for $2 \mathrm{~h}$ abolished the signal, demonstrating that ROS is transiently produced as a result of pollen activation (Figure $2 \mathrm{~d}$ ). We also used the nitroblue tetrazolium (NBT) assay, which detects the presence of superoxide anion. After
NBT treatment, we found formation of formazan deposits, indicating the presence of ROS. These three assays demonstrate that pollen collected from honey bee corbiculae possesses the ability to produce ROS upon rehydration (Figure 2e).

\subsection{Pollen in honey bee midgut contents produces ROS}

We found a robust signal of ROS in the food bolus of individual bees using the indicator CM-H2DCFDA. The signal was often present in structures that appeared to be pollen grains (Figure 3a). Using the Amplex Red assay, we found variable signal in food boluses of individual bees (Figure $3 \mathrm{~b}$ ). When boluses were pooled, signal could be eliminated through the addition of NAC or AA, demonstrating the signal is specific for ROS (Figure 3c).

The above sampled bees were foragers, which are thought to consume relatively little pollen (Crailsheim et al. 1992; Crailsheim et al. 1993; Hrassnigg and Crailsheim 1998) in part because of their minimal ability to digest it (Moritz and Crailsheim 1987). However, we consistently found some pollen in the midguts of returning foragers, perhaps suggesting sampling of pollen or accidental ingestion at the flower. If so, foragers that return to 
a

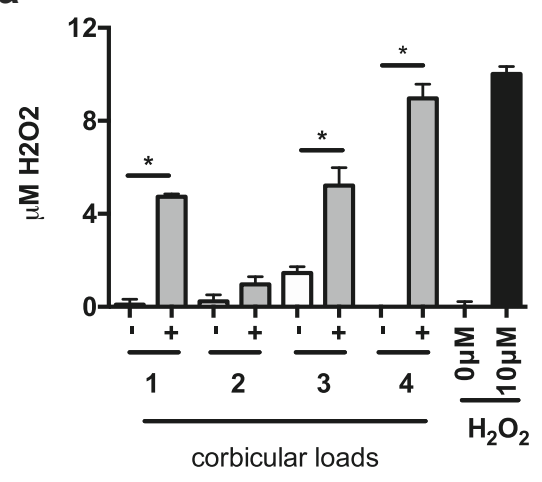

C

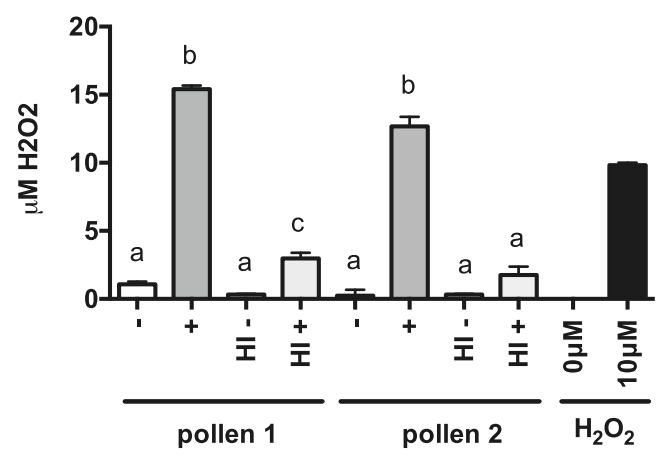

b

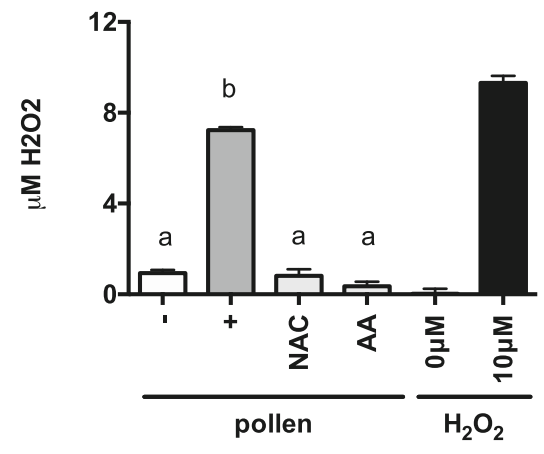

d

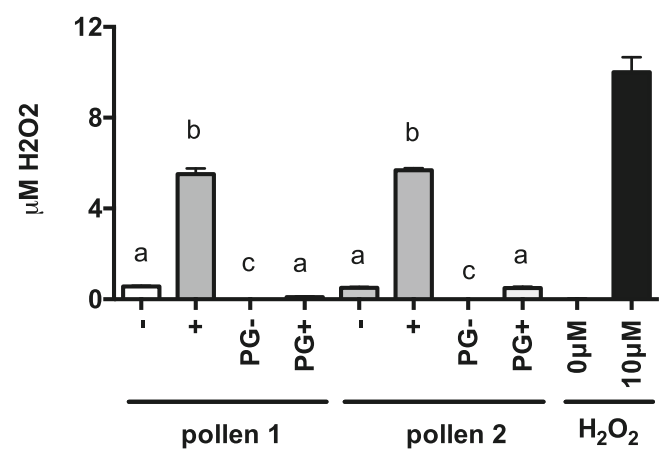

e

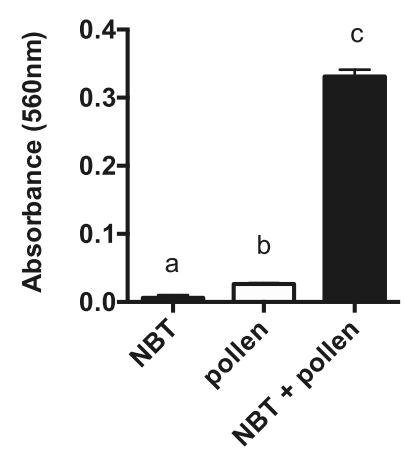

Figure 2. ROS production in honey bee-collected pollen is sensitive to anti-oxidants and heat inactivation. $\mathbf{a}-\mathbf{d}$ Results of Amplex Red Assay. $\mathrm{H}_{2} \mathrm{O}_{2}$ standards are presented on the far right; + and - represent with or without dye. a $\mathrm{H}_{2} \mathrm{O}_{2}$ production by bee-collected pollen grains from four different corbicular loads (numbered $1-4$ on $x$-axis) harvested on the same day. b $\mathrm{H}_{2} \mathrm{O}_{2}$ production by bee-collected pollen grains with or without $\mathrm{N}$-acetyl cysteine (NAC) or ascorbic acid (AA). $\mathrm{c}_{2} \mathrm{O}_{2}$ production by bee-collected pollen grains with or without heat inactivation (HI). (D) $\mathrm{H}_{2} \mathrm{O}_{2}$ production by bee-collected pollen grains with or without pre-germination (PG). e Superoxide anion production by pollen grains demonstrated by NBT assay. Data is represented as mean \pm SEM. $* p<0.05, * * p<0.01$, $\mathrm{a} \neq \mathrm{b} \neq \mathrm{c} p<0.05$

the nest without pollen in their corbiculae might represent nectar foragers and therefore be expected to have ingested little pollen. When comparing the gut contents of returning 
a

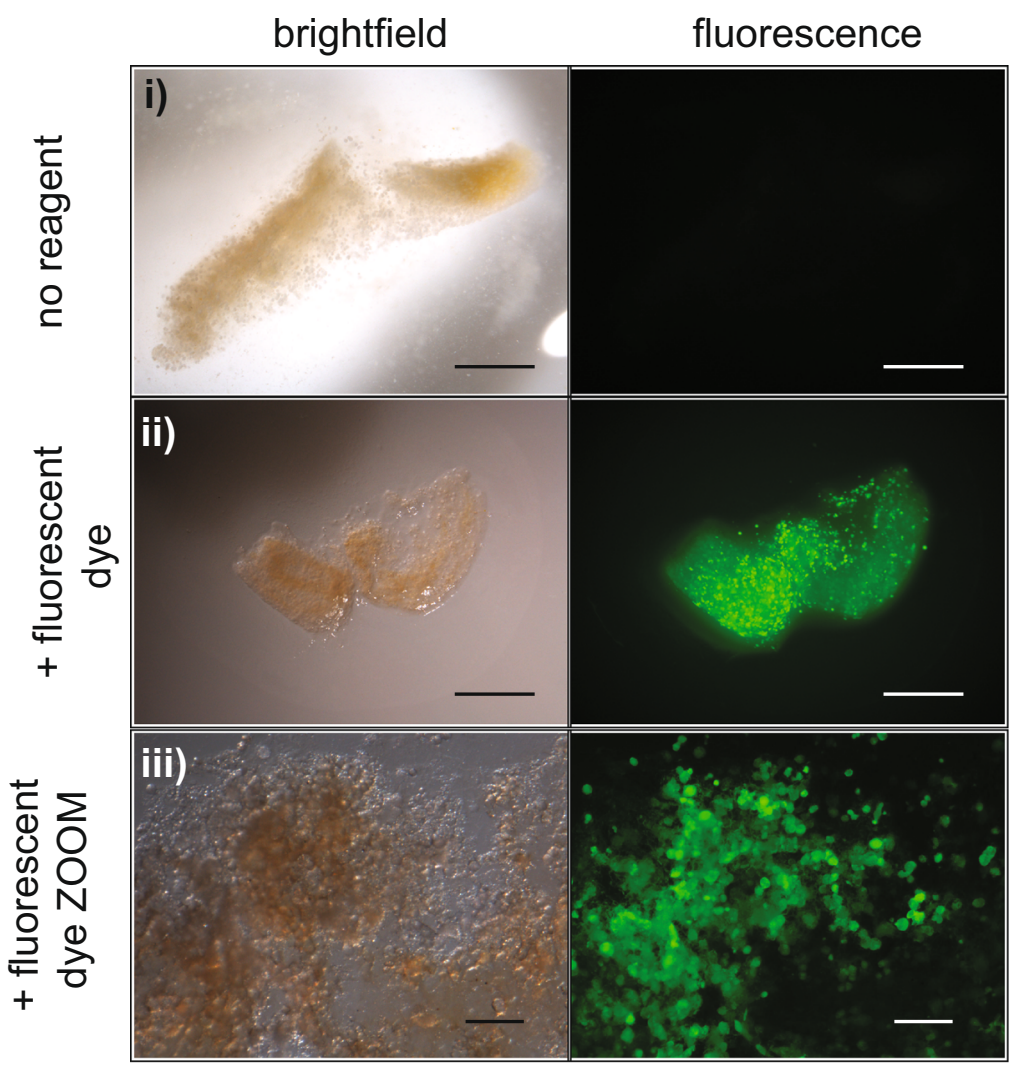

b

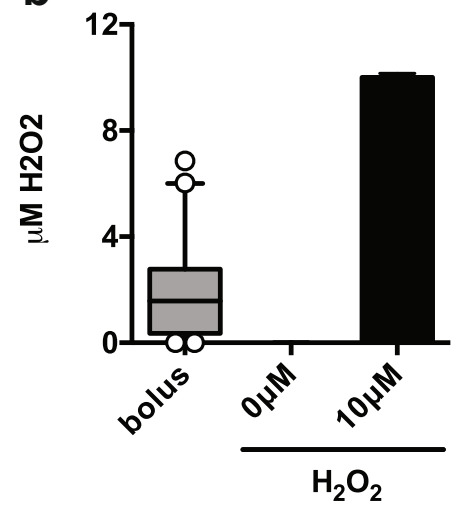

C

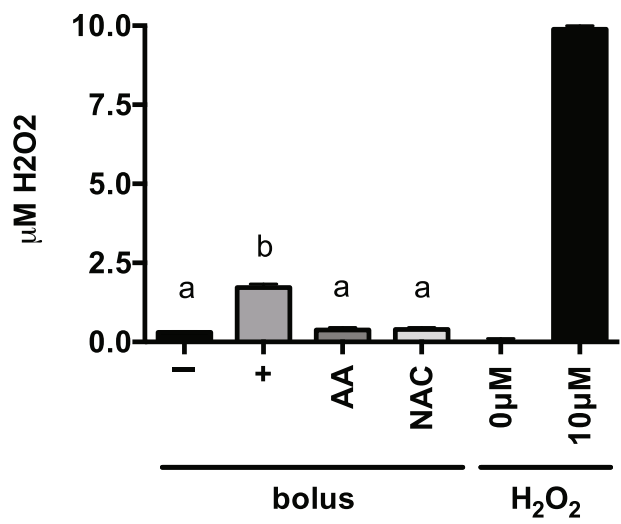

Figure 3. ROS production in honey bee food boluses. a Food bolus contents assayed for ROS presence using CM$\mathrm{H}_{2}$ DCF. Fluorescence indicates ROS. From top: (i) bolus with no CM- $\mathrm{H}_{2} \mathrm{DCF}$ dye, (ii) bolus with CM- $\mathrm{H}_{2} \mathrm{DCF} d y e$ (iii) bolus with $\mathrm{CM}-\mathrm{H}_{2} \mathrm{DCF} d y e$ at higher magnification. Left panels are brightfield images, right panels are phasecontrast images of each bolus (scale bar $=0.1 \mathrm{~mm}$ for $\mathrm{i} / \mathrm{ii}$ and $0.5 \mathrm{~mm}$ for iii). $\mathbf{b} \mathrm{H}_{2} \mathrm{O}_{2}$ production by food boluses from forager honey bees detected by the Amplex Red assay. Plot shows 1st and 3rd interquartile range with lines denoting medians. Whiskers encompass $95 \%$ of the individuals. Outliers are denoted with circles. c $\mathrm{H}_{2} \mathrm{O}_{2}$ production by food boluses from forager honey bees with or without $\mathrm{N}$-acetyl cysteine (NAC) or ascorbic acid (AA) detected by the Amplex Red assay; + and - represent with or without dye. Data is represented as mean $\pm \mathrm{SEM}$. $* p<0.05, * * p<0.01, \mathrm{a} \neq \mathrm{b} p<0.05$. 
foragers that were carrying pollen to those that were not, we did in fact observe observed that bees with pollen in their corbiculae had more pollen in their midgut contents than returning bees not carrying pollen and more ROS (Figure 4a, b).

\subsection{Honey bee pollen consumption results in $\mathrm{ROS}$ production}

To demonstrate that preventing ingestion of pollen lowers levels of ROS in the gut, we collected returning foragers with pollen loads and measured the midgut ROS levels in one group immediately. We fed the remaining group a pollen-free diet for $24 \mathrm{~h}$, and then measured ROS levels. We found that ROS levels and pollen counts both declined in bees fed a pollen free diet for $24 \mathrm{~h}$, compared with foragers that were sampled immediately upon return (Figure 5a, b). please check Figure 5.

To demonstrate that pollen consumption leads to increased levels of ROS in honey bee midguts, we fed bees sucrose syrup for $24 \mathrm{~h}$, starved them for $1 \mathrm{~h}$, then fed them either sucrose syrup alone or sucrose syrup supplemented with $50 \mathrm{mg} / \mathrm{ml}$ fresh pollen for $1 \mathrm{~h}$. We observed increased ROS levels (Figure 5c) and pollen counts (Figure 5d) in bees fed sucrose syrup with pollen compared with those receiving sucrose syrup alone for the same time period.

\section{DISCUSSION}

We observe that honey bee-collected pollen from multiple plant species can produce ROS, both in vitro and in the honey bee gut. We also observe that ROS is extinguished by antioxidants and that its production can be reduced by heat inactivation or by pre-germination of pollen samples, providing strong evidence that honey beecollected pollen retains some metabolic activity that is initiated upon exposure to fluid, potentially representing partial or pseudo germination.

Most studies of germination potential postcollection have focused on pollen tube formation or fertilization potential (Roulston and Cane 2000). These are late events in the germination process and loss of these functions is not necessarily associated with loss of the ability to initiate the germination process. By focusing on metabolic activity associated with early germination processes, our results support a mechanism in which pollen grains collected by bees can initiate the germination process. In fact, retained metabolic activity would be essential for initiation of psuedogermination even as an interrupted process. Our results are consistent with earlier studies
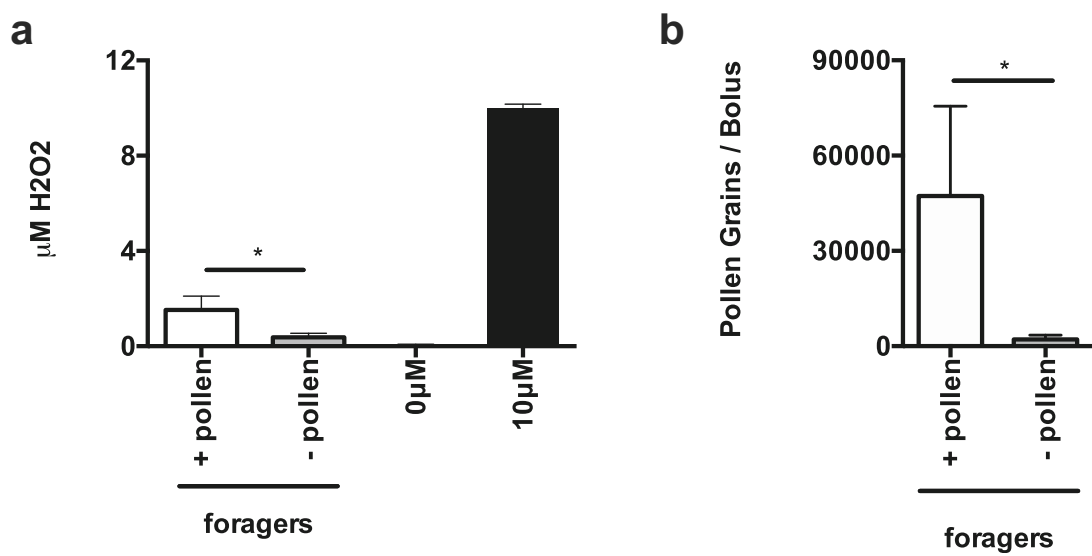

Figure 4. Foragers returning with pollen have higher pollen counts and higher ROS levels in the food bolus. a $\mathrm{H}_{2} \mathrm{O}_{2}$ production as detected by the Amplex Red assay and $\mathbf{b}$ pollen counts as assessed by Safranin O staining in food boluses from forager honey bees with $(+, n=11)$ or without $(-, n=11)$ corbicular loads containing pollen. Data is represented as mean \pm SEM. $* p<0.05, * * p<0.01, \mathrm{a} \neq \mathrm{b} p<0.05$. 
A

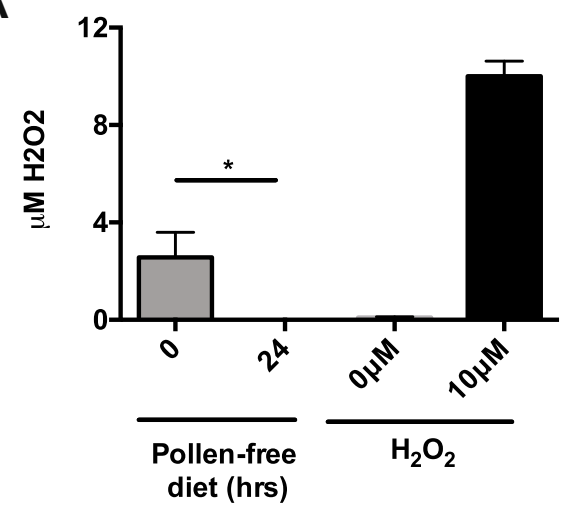

C

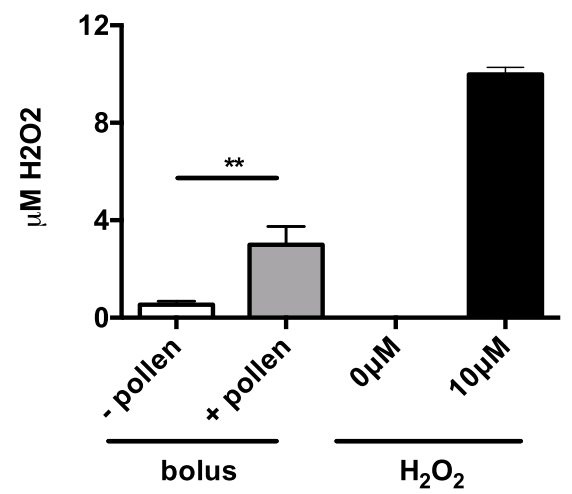

B

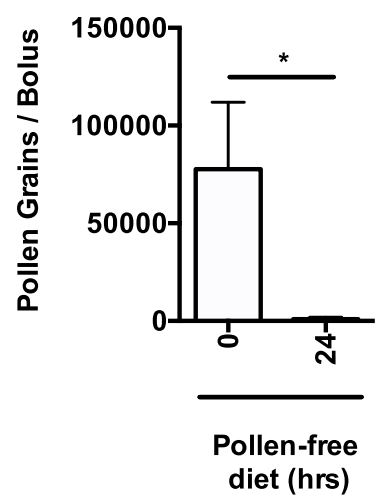

D

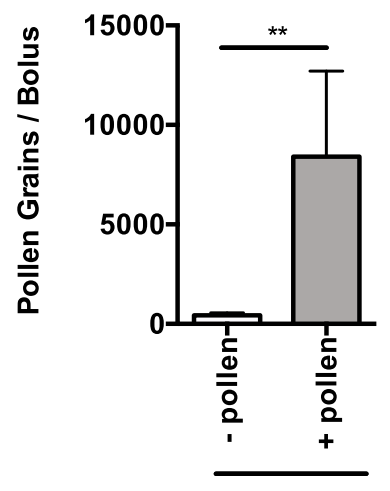

$1 \mathrm{hr}$ feeding

Figure 5. Manipulation of pollen levels in the midgut changes ROS levels in the food bolus. a $\mathrm{H}_{2} \mathrm{O}_{2}$ production as detected by the Amplex Red assay (" 0 ", $n=7$ ) and after (" $24 ", n=9$ ) and b pollen counts (" 0 ", $n=5$ ) and after (" 24 ", $\mathrm{n}=5$ ) as assessed by Safranin O staining in food boluses from forager honey bees before being maintained on a pollen-free diet for $24 \mathrm{~h}$. $\mathrm{c} \mathrm{H}_{2} \mathrm{O}_{2}$ production as detected by the Amplex Red assay and d pollen counts as assessed by Safranin O staining in food boluses from forager bees immediately after collection $(n=7)$ or after being fed pollen for $1 \mathrm{~h}(\mathrm{n}=7)$. Data is represented as mean \pm SEM. *p $<0.05, * * \mathrm{p}<0.01, \mathrm{a}^{1} \mathrm{~b} \mathrm{p}<0.05$

that found that bee-collected pollen showed a significant increase in $\mathrm{O}_{2}$ uptake relative to ungerminated pollen (Keularts and Linskens 1968; Verhoef and Hoekstra 2012), supporting retained metabolic activity despite absence of pollen tube formation. Future studies of early germination processes (e.g., through the use of $\mathrm{Ca}^{2+}$ flux ((Steinhorst and Kudla 2013), structural cellular changes (Vogler et al. 2015), and transcriptomics and proteomics (Ambrosino et al. 2016)) may provide additional understanding of pollen digestion in this species. By investigating these earlystage cellular components and processes in the honey bee gut, future studies may yield additional information that cannot be captured in studies of pollen tube formation or fertilization potential alone.

We observed significant differences between the ROS production by pollen representing different plant species and even differences in the levels of ROS in pollen from the same species. While it is interesting to speculate about the significance of the observed differences between species, there are a number of caveats to such comparisons in this assay. First, pollen from different species is known to possess quite different requirements for initiation of germination, including media components and time after hydration. Therefore, it is 
quite possible that our PBS-based germination media is not appropriate for germination of certain pollen types. Second, other pollen indices, such as protein content and viability, are known to vary extensively between members of the same species, based on genotypic and environmental influences on plant health (Marshall et al. 2010; Yeamans et al. 2014). For example, pollen is known to lose germination potential under a number of conditions in a species-specific manner. A variable known to affect germination is the time since production in the anther. This ability is dependent on whether the species produces pollen of the orthodox (low-metabolism) or recalcitrant (himetabolism) type (Hashida et al. 2013). Flowering plants generally produce pollen in a narrow window of time and we are unable to accurately determine the age of the pollen used in the assay. In addition, the pollen type of each species has not always been described, making it difficult to predict pollen longevity and ROS activity.

In addition to our in vitro assays, we also find that ROS can be readily found in the lumen of the digestive tract of honey bees and appears localized to pollen grains, suggesting that initiation of metabolic activity occurs to some extent during the pollen digestion process. Furthermore, manipulating pollen levels in the midgut can change ROS levels in the digestive tract; an increase in gut pollen through feeding leads to an associated increase in ROS in the lumen, while a decrease in pollen feeding by feeding sucrose solution alone leads to a decrease in ROS. It is important to note that changes in ROS levels in the midgut could also be due to alterations in metabolism of the epithelial cells in response to the presence or absence of pollen in the diet. In addition, increased ROS levels in the midgut after feeding could also be due to ROS production by the epithelial cells in response to oral exposure to microbes, as has been shown in other invertebrate midguts (reviewed in (Lee et al. 2017)). A similar inducible ROS system has been proposed in honey bees (Kawahara et al. 2007; Dussaubat et al. 2012). However, in a separate series of experiments, we did not observe any evidence of increased ROS production after feeding bees either the pathogenic bacterium Serratia marcescens or the proposed cellular agent of inducible ROS production (the DUOX ligand uracil) (data not shown). In addition, we observed that ROS in the gut lumen was localized to pollen grains, which seems an unlikely finding if changes in ROS levels in the midgut were due to ingestion induced ROS production by the epithelial cells.

In addition to providing potential insight into pollen digestion, the observed increase in ROS levels after pollen consumption may have other implications for honey bee health. Previous work has shown that ROS produced by pollen from wind-pollinated species may damage the barrier epithelial tissue of the airway in humans in the context of allergic inflammation (Boldogh et al. 2005; Bacsi et al. 2005; Wang et al. 2009; Speranza and Scoccianti 2012). Pollen-derived ROS could have significant effects on the biology of the barrier epithelia in the honey bee as well. First, ROS could cause damage to epithelial cells and impact barrier epithelial function, as has been reported after chemical induced ROS exposure in fruit fly digestive tract (Chatterjee and Ip 2009; Buchon et al. 2009). Second, pollen-derived ROS could negatively impact the microbiota of the digestive tract by exposing the resident bacteria to this antimicrobial compound (Lee et al. 2013).

Significant further study is needed to fully understand the impacts of the pollen associated ROS on honey bees in the context of the colony. Pollen consumption by worker honey bees is quite variable and depends on developmental stage and age. Pollen represents less than $5 \%$ of the total protein consumed during larval development (Babendreier et al. 2004), in contrast to the large quantities of pollen that young workers consume after they emerge as adults from their cells (Hagedorn and Moeller 1967; Dietz 1969). Thus, adult workers are the group that is most likely to consume pollen and be affected by ROS production. However, honey bee workers also exhibit an age-based societal structure, in which a major behavioral transition occurs with a switch from nursing inside the nest to foraging outside (Winston 1987). One hallmark of this transition is reduced protein consumption, manifested as a reduction in both the amount of pollen a worker 
ingests (Crailsheim et al. 1992; Crailsheim et al. 1993; Hrassnigg and Crailsheim 1998) and her ability to digest pollen due to reduced production of digestive enzymes (Moritz and Crailsheim 1987). Thus, the effect of ROS production (and potentially pseudogermination) during pollen digestion will likely differ between workers of different classes within colonies, and may impact foraging and feeding decisions on both individual and colony levels.

Here, we provide evidence of preserved metabolic activity in pollen collected and consumed by honey bees. Such retained metabolic activity would be essential for initiation of psuedogermination events and thus these data provide additional support for a mechanism of pollen digestion that includes pseudogermination in honey bees, and points to novel approaches for better understanding of pollen digestion in this species and other palynivorous insects.

\section{ACKNOWLEDGMENTS}

The authors acknowledge Heather Mattila for helpful comments about this study.

\section{AUTHORS' CONTRIBUTIONS}

MM, SRP, and JWS conceived and designed the experiments. MM, SRP, TRA, and JWS performed experiments and analyzed the data. All authors contributed to the drafting and revision of the article.

\section{COMPLIANCE WITH ETHICAL STANDARDS}

Conflict of interest The authors declare that they have no conflict of interest.

Le maintien de l'activité métabolique du pollen a des répercussions sur la digestion du pollen et des effets sur la santé des abeilles.

écologie / abeilles mellifères / pollen / pollinisateur / digestion.
Reste metabolischer Aktivität in Honigbienenpollen sind von Bedeutung für die Pollenverdauung und die Gesundheit von Honigbienen.

\section{Ökologie / Honigbiene / Pollen / Bestäuber / Verdauung.}

\section{REFERENCES}

Ambrosino L, Bostan H, Ruggieri V, Chiusano ML (2016) Bioinformatics resources for pollen. Plant Reproduction 29:133-147. doi: https://doi.org/10.1007/s00497016-0284-8

Anderson KE, Carroll MJ, Sheehan T, et al (2014) Hivestored pollen of honey bees: many lines of evidence are consistent with pollen preservation, not nutrient conversion. Mol Ecol 23:5904-5917. doi: https://doi. org/10.1111/mec. 12966

Babendreier D, Kalberer N, Romeis J, et al (2004) Pollen consumption in honey bee larvae: a step forward in the risk assessment of transgenic plants. Apidologie 35:293-300. doi: https://doi.org/10.1051 /apido:2004016

Bacsi A, Dharajiya N, Choudhury BK, et al (2005) Effect of pollen-mediated oxidative stress on immediate hypersensitivity reactions and late-phase inflammation in allergic conjunctivitis. J Allergy Clin Immunol 116:836-843. doi: https://doi.org/10.1016/j. jaci.2005.06.002

Betts AD (1935) The constancy of the pollen-collecting bee. Journal of Horticultural Science 16:111-113.

Boldogh I, Bacsi A, Choudhury BK, et al (2005) ROS generated by pollen NADPH oxidase provide a signal that augments antigen-induced allergic airway inflammation. J Clin Invest 115:2169-2179. doi: https://doi. org/10.1172/JCI24422

Brodschneider R, Gratzer K, Heigl H, et al. 2018 What we can (or cannot) learn from multifloral pollen pellets. Bee World 95:78-80. doi: https://doi.org/10.1080 /0005772X.2018.1483057

Buchon N, Broderick NA, Chakrabarti S, Lemaitre B (2009) Invasive and indigenous microbiota impact intestinal stem cell activity through multiple pathways in Drosophila. Genes Dev 23:2333-2344. doi: https://doi. org/10.1101/gad.1827009

Chatterjee M, Ip YT (2009) Pathogenic stimulation of intestinal stem cell response in drosophila. J Cell Physiol 220:664-671. doi: https://doi.org/10.1002 /jcp. 21808

Chen S, Yao H, Han J, et al (2010) Validation of the ITS2 Region as a Novel DNA Barcode for Identifying Medicinal Plant Species. PLoS ONE 5:e8613. doi: https://doi.org/10.1371/journal.pone.0008613.t003 
Crailsheim K, Schneider L, Hrassnigg N, et al (1992) Pollen consumption and utilization in worker honeybees (Apis mellifera carnica): dependence on individual age and function. J Insect Physiol 38:409-419.

Crailsheim K, Hrassnigg N, Gmeinbauer R, et al (1993) Pollen Utilization in Non-Breeding Honeybees in Winter. J Insect Physiol 39:369-373. doi: https://doi. org/10.1016/0022-1910(93)90024-L

Dietz A (1969) Initiation of pollen consumption and pollen movement through the alimentary canal of newly emerged honey bees. Annals of the Entomological Society of America. 62:43-46. https://doi. org/10.1093/aesa/62.1.43

Dussaubat C, Brunet J-L, Higes M, et al (2012) Gut Pathology and Responses to the Microsporidium Nosema ceranae in the Honey Bee Apis mellifera. PLoS ONE 7:e37017. doi: https://doi.org/10.1371/journal. pone. $0037017 . t 001$

Free JB, Durrant AJ (1966) The transport of pollen by honey-bees from one foraging trip to the next. Journal of Horticultural Science, 41:187-89. doi: https://doi. org/10.1080/00221589.1966.11514157

Gilliam M (1997) Identification and roles of nonpathogenic microflora associated with honey bees (vol 155, pg 1, 1997). FEMS Microbiology Letters 157:219-219

Griggs WH, Vansell GH (1950) The Germinating Ability of Quick Frozen, Bee-Collected Apple Pollen Stored in a Dry Ice Container. Journal of Economic Entomology 43(4):549-549

Griggs W, Vansell G, Lwakiri B (1953) Pollen storage: High viability of pollen obtained after storage in home freezer. Calif Agr 7:12

Hagedorn HH, Moeller FE (1967) The Rate of Pollen Consumption by Newly Emerged Honeybees. Journal of Apicultural Research 6:159-162. doi: https://oi. org/10.1080/00218839.1967.11100176

Hashida S-N, Kawai-Yamada M, Uchimiya H (2013) NAD (+) accumulation as a metabolic off switch for orthodox pollen. psb. doi: https://doi.org/10.4161 /psb.23937

Hrassnigg N, Crailsheim K (1998) The influence of brood on the pollen consumption of worker bees (Apis mellifera L.). J Insect Physiol 44:393-404.

Human H, Nicolson SW (2003) Digestion of maize and sunflower pollen by the spotted maize beetle Astylus atromaculatus (Melyridae): is there a role for osmotic shock? J Insect Physiol 49:633-643. doi: https://doi. org/10.1016/S0022-1910(03)00049-0

Human H, Nicolson SW (2006) Nutritional content of fresh, bee-collected and stored pollen of Aloe greatheadii var. davyana (Asphodelaceae). Phytochemistry 67:1486-1492. doi: https://doi.org/10.1016 /j.phytochem.2006.05.023

Johansen C (1956) Artificial Pollination of Apples with Bee-Collected Pollen. Journal of Economic Entomology 49:825-828.
Jones GD (2012) Pollen extraction from insects. Palynology 36:86-109. doi: https://doi.org/10.1080 /01916122.2011.629523

Kawahara T, Quinn MT, Lambeth JD (2007) Molecular evolution of the reactive oxygen-generating NADPH oxidase (Nox/Duox) family of enzymes. BMC Evol Biol 7:109. doi: https://doi.org/10.1186/1471-2148-7-109

Keularts J, Linskens HF (1968) Influence of fatty acids on petunia pollen grains. Acta Botanica Neerlandica 17:267-272

Klungness LM, Peng YS (1983) A scanning electron microscopic study of pollen loads collected and stored by honeybees. Journal of Apicultural Research 22:264 271

Klungness M, Thorp R, Briggs D (1983) Field testing the germinability of almond pollen (Prunus dulcis). Journal of Horticultural Science 58(22):29-235

Klungness LM, Peng YS (1984a) A histochemical study of pollen digestion in the alimentary canal of honeybees ( Apis mellifera L.). J Insect Physiol Elsevier 30:511-521

Klungness LM, Peng YS (1984b) Scanning electron microscope observations of pollen food bolus in the alimentary canal of honeybees (Apis mellifera L.). Canadian journal of zoology. NRC Research Press 62:1316-1319

Koetschan C, Forster F, Keller A, et al (2009) The ITS2 Database III-sequences and structures for phylogeny. Nucleic Acids Research 38:D275-D279. doi: https://doi.org/10.1093/nar/gkp966

Kraai A (1962) How long do honey-bees carry germinable pollen on them? Euphytica 11:53-56

Kroon GH, van Praagh JP, Velthuis HHW (1974) Osmotic shock as a prerequisite to pollen digestion in the alimentary tract of the worker honeybee. Journal of Apicultural Research 13:177-181.

Lee K-A, Kim S-H, Kim E-K, et al (2013) BacterialDerived Uracil as a Modulator of Mucosal Immunity and Gut-Microbe Homeostasis in Drosophila. Cell 153:797-811. doi: https://doi.org/10.1016/j. cell.2013.04.009

Lee J-H, Lee K-A, Lee W-J (2017) Microbiota, Gut Physiology, and Insect Immunity. Advances in Insect Physiology 52:111-138. doi: https://doi.org/10.1016/bs. aiip.2016.11.001

Marshall DL, Avritt JJ, Maliakal-Witt S, et al (2010) The impact of plant and flower age on mating patterns. Ann Bot 105:7-22. doi: https://doi.org/10.1093 /aob/mcp260

Masood M, Everett CP, Chan SY, Snow JW (2016) Negligible uptake and transfer of diet-derived pollen microRNAs in adult honey bees. rnabiology 13:109118 . doi: https://doi.org/10.1080 /15476286.2015.1128063

McInnis SM, Desikan R, Hancock JT, Hiscock SJ (2006) Production of reactive oxygen species and reactive nitrogen species by angiosperm stigmas and pollen: potential signalling crosstalk? New Phytologist 
172:221-228. doi: https://doi.org/10.1111/j.14698137.2006.01875.x

Mesquida J, Renard M (1989) Etude de 1"aptitude à germer in vitro du pollen de colza (Brassica napus L.) récolté par 1"abeille domestique (Apis mellifica L.). Apidologie 20:197-205.

Moritz B, Crailsheim K (1987) Physiology of Protein Digestion in the Midgut of the Honeybee (Apis-Mellifera L). J Insect Physiol 33:923-931.

Nicolson SW, Human H (2013) Chemical composition of the "low quality" pollen of sunflower (Helianthus annuus, Asteraceae). Apidologie 44:144-152. doi: https://doi.org/10.1007/s13592-012-0166-5

Peng YS, Nasr ME, Marston JM (1985) The digestion of dandelion pollen by adult worker honeybees. Physiological entomology 10:75-82

Peng YS, Nasr ME, Marston JM (1986) Release of alfalfa, Medicago sativa, pollen cytoplasm in the gut of the honey bee, Apis mellifera (Hymenoptera: Apidae). Annals of the Entomological Society of America. Entomological Society of America 79:804-807

Peng YS, Dobson HEM (1997) Digestion of Pollen Components by Larvae of the Flower-Specialist Bee Chelostoma florisomne (Hymenoptera: Megachilidae). J Insect Physiol 43:89-100.

Potts SG, Imperatriz-Fonseca V, Ngo HT, et al (2016) Safeguarding pollinators and their values to human well-being. Nature 540:220-229. doi: https://doi. org/10.1038/nature20588

Rook G, Steele J, Umar S, Dockrell HM (1985) A simple method for the solubilisation of reduced NBT, and its use as a colorimetric assay for activation of human macrophages by $\gamma$-interferon. J Immunol Methods 82:161-167.

Roulston TH, Cane JH (2000) Pollen nutritional content and digestibility for animals. Plant Systematics and Evolution 222:187-209.

Singh S, Boynton D (1949) Viability of apple pollen in pollen pellets of honeybees. Proc Am Soc Hort Sc 53:148-153.

Speranza A, Scoccianti V (2012) New insights into an old story: Pollen ROS also play a role in hay fever. psb 7:994-998.
Steinhorst L, Kudla J (2013) Calcium - a central regulator of pollen germination and tube growth. Biochim Biophys Acta 1833:1573-1581. doi: https://doi. org/10.1016/j.bbamcr.2012.10.009

Vaissiere BE, Malaboeuf F, Rodet G (1996) Viability of cantaloupe pollen carried by honeybeesApis mellifera varies with foraging behavior. Naturwissenschaften 83:84-86. doi: https://doi.org/10.1007/bf01141876

Verhoef H, Hoekstra FA (2012) Absence of 10-hydroxy-2decenoic acid (10-HDA) in bee-collected pollen. In: Mulcahy DL (ed) Biotechnology and Ecology of Pollen: Proceedings of the International Conference on the Biotechnology and Ecology of Pollen, 9-11 July, 1985, University of .... Springer New York, New York, pp 391-396

Vogler F, Konrad SSA, Sprunck S (2015) Knockin“ on pollen"s door: live cell imaging of early polarization events in germinating Arabidopsis pollen. Front Plant Sci 6:1-17. doi: https://doi.org/10.3389 /fpls.2015.00246

Wang X-L, Takai T, Kamijo S, et al (2009) NADPH oxidase activity in allergenic pollen grains of different plant species. Biochem Biophys Res Commun 387:430-434. doi: https://doi.org/10.1016/j. bbrc.2009.07.020

Waser NM, Ollerton J (eds) (2006) Plant-pollinator interactions: From specialization to generalization. Chicago, IL

Winston ML (1987) The Biology of the Honey Bee. Harvard University Press, Cambridge, MA

Wright GA, Nicolson SW, Shafir S (2018) Nutritional Physiology and Ecology of Honey Bees. Annual Review of Entomology 63:327-344. doi: https://doi. org/10.1146/annurev-ento-020117-043423

Yeamans RL, Roulston TH, Carr DE (2014) Pollen quality for pollinators tracks pollen quality for plants in Mimulus guttatus. Ecosphere. doi: https://doi. org/10.1890/ES14-00099.1

Publisher's note Springer Nature remains neutral with regard to jurisdictional claims in published maps and institutional affiliations. 